\title{
A Possible Framework for the Design of Learning Programs in Assistive Technology for People with Intellectual Disabilities in Inclusive Educational Environments
}

\author{
Ivan Traina ${ }^{1}$, Evert Jan Hoogerwerf ${ }^{2}$ \\ ${ }^{1}$ National University of Ireland Galway, School of Psychology, Galway, Ireland \\ ${ }^{2}$ AIAS Bologna Onlus, Bologna, Italy
}

Email address:

ivan.traina $a$ nuigalway.ie (I. Traina), hoogerwerf $@$ ausilioteca.org (E. J. Hoogerwerf)

\section{To cite this article:}

Ivan Traina, Evert Jan Hoogerwerf. A Possible Framework for the Design of Learning Programs in Assistive Technology for People with Intellectual Disabilities in Inclusive Educational Environments. Psychology and Behavioral Sciences. Vol. 7, No. 2, 2018 , pp. $29-37$. doi: $10.11648 /$ j.pbs.20180702.11

Received: May 15, 2018; Accepted: June 26, 2018; Published: July 23, 2018

\begin{abstract}
In an inclusive society, people with Intellectual Disabilities (ID) are socially connected and fully participate in all realms of life, including education and employment. In a digital society being able to use technology for learning and working is a condition for participation and not remaining behind. For that reason, efforts should be made to assure that all citizens have access to technology and are helped, if needed, to develop their digital skills. The objective of this paper is to provide a framework for designing learning programs addressed to people with ID. The aims of these programs would be to support the development of digital skills and enable the use of Assistive Technologies (AT) or the combination of Information Communication Technology and AT (ICT-AT). The framework provided is based on the European funded project "Keeping Pace with Assistive Technology (KPT)" that was adapted for the specific target group of people with ID.
\end{abstract}

Keywords: Learning Programs, People with Intellectual Disabilities, ICT-AT, Inclusion, Educational Environments

\section{Introduction}

This article is aimed at providing suggestions to enhance the development of competences of people with Intellectual Disabilities (ID) in the use of Assistive Technology (AT), to develop their full potential and to reach higher personal outcomes in learning, working and living independently.

The World Report on Disability of the World Health Organization (WHO) states that about $15 \%$ of the world's population lives with some form of disability, of whom 2-4\% experience significant difficulties in functioning, while 1-3\% of the general population is affected by intellectual disability [1].

The importance of technology in current digital society is evident, while policies to make that digital society more inclusive should consist in shaping the conditions for peoples' participation and not remaining behind in learning and employment. For that reason, efforts should be made to assure that all citizens have access to technology and develop their digital skills in order to boost personal outcomes. This is highlighted also by the WHO, that recognizes the importance of access to assistive technologies, as showed by the recent adoption of Resolution EB142. R6 (improving access to $\mathrm{AT}^{1}$ ) by the World Health Organization Executive Board [2].

The existing literature indicates lack of appropriate training and support as well as negative attitudes, as a barrier to supporting AT competencies' development for people with disabilities [3].

The adoption of new technologies for the empowerment of learners with disabilities in mainstream education, implies the adoption of new approaches and the provision of adequate training to all stakeholders involved [4]. An effective integration of AT into educational environments will depend on the ability of teachers/trainers to structure new learning processes and classroom settings, based on Universal Design principles [5, 6], in order "to merge new technology with a new pedagogy, to develop active

1 http://apps.who.int/gb/ebwha/pdf_files/WHA71/A71_21-en.pdf 
classrooms, encouraging co-operative interaction, collaborative learning and group work" [7]. This requires a different set of skills, including the ability to develop ways of using innovative solutions to encourage technology literacy.

The 2030 Agenda for Sustainable Development has defined 17 Sustainable Development Goals ${ }^{2}$. In particular Goal 4 - "Ensure inclusive and quality education for all and promote lifelong learning", details as key policy issue to "Ensure inclusive and equal access to ICT devices and online resources to the poor, to women and girls, to people with disabilities, and to learners in geographically isolated areas".

Access to training in technological developments and its potential benefit is a crucial component for improving educational environments. According to Fullan and Langworthy [8] research findings indicate that technology has a low impact on learning, because teachers and trainers don't find effective ways to use technology to support learning needs. It also includes the lack of understanding and competences involving new technologies, inadequate training and lack of incentives [9-11].

Even when technology is present in education and it matches with the needs or the wishes of learners, the presence of digital technologies in the educational environment in itself is not sufficient. If students are not supported in mastering methods to make effective use of it in different learning and future employment contexts they will not be successful.

In order to lead to higher personal outcomes effective learning and training in the use of AT is needed.

Currently, AT is not an independent discipline in Europe. Most learning in this field builds on training activities carried out by professionals coming from different professional background (e.g. speech and language therapy, physiotherapy, occupational therapy), not only from educational and teaching environments.

Where training is provided it often targets professional users of ICT-AT (engineers, technologists, trainers, teachers and carers), for whom supporting the correct use of innovative technological devices is part of their working field. In contrast with the objectives of many educational institutions to empower learners, not much AT training is delivered for people with ID themselves.

For this reason, there is a need for a methodology for developing AT related learning programs in educational environments targeting people with ID. A methodology, already developed in the framework of the European funded project "Keeping pace with $\mathrm{AT}^{\prime \prime}$, is taken as a starting point and is here adapted to specifically address the learning needs of people with ID.

Before presenting the methodology, it is important to clarify some concepts used in this article, in order to point out to readers the meaning of the terms included in the

\footnotetext{
2 http://www.un.org/sustainabledevelopment/

3https://www.up2europe.eu/european/projects/keeping-pace-with-assistivetechnology_122371.html
}

framework of reference.

\subsection{Learning Programs}

"Learning programs" are here intended as structured educational pathways or curricula that can be defined as "what is learned and what is taught (context), how it is delivered (teaching - learning methods), the learned is assessed (e.g. forms of evaluation); and the resources needed" [12].

The availability of examples of learning programs (or curricula) and teaching practices are conditions for moving towards AT facilitated inclusive education.

In general, learning programs in inclusive educational environments must be flexible and adaptable and designed to overcome environmental barriers that disadvantaged learners meet in regular education.

An example of a learning program based on the use of AT addressed to young people with ID is the "Job TIPS program ${ }^{4} "$. This is a multimedia employment training program that through mind-based guidance, video models, visual supports, and virtual reality practice offers five sections to support the individual with Autism Spectrum Disorder (ASD). This enables them to face the process of determining career interests, finding a job, getting a job, keeping a job, and other job-related topics.

An example of how the use of AT can enhance learning is provided by the App "Social Skills Animation"." It allows the transformation of social story or a comic strip to animation with the use of a PC, tablet or smart phone and present it to the person they are supporting for targeted therapeutic reasons, e.g. Speech and Language therapists or other professionals working with individuals with social and/or communication needs.

Finally, an example of App that brings together both aspects, training in the use of AT and learning through the use of AT is AVAIL ${ }^{6}$. This is an educational platform that promotes learning and independence for children and adults with ID. It maximizes the learner's personal strengths providing a guide for parents or care staff to create individualized, step-by-step instructions of daily tasks using videos, picture, audio and text prompts.

\subsection{AT and People with Intellectual Disabilities}

AT can help transform static media (e.g. printed books) into flexible digital media made accessible to people with ID (e.g. Easy to Read, alternative and augmentative communication, use of audio visuals). This can be achieved by the deployment of mainstream or specially designed hardware and software (e.g. pc's, tablets, audio-books).

As previous research has shown [13], effective use of appropriate AT can contribute to enhance the independence and community participation of people with ID [14].

Therefore, the primary audience of the learning programs

4 https://www.Do2Learn.com/JobTIPS

$5 \mathrm{https}$ ://socialskillsanimation.com

$6 \mathrm{https} / / /$ www.availsupport.ie/ 
developed according to the methodology is represented by people with ID of different ages.

Since the methodology is flexible, it can be adopted in primary and secondary schools, but also in in-formal and non-formal contexts where people with ID can benefit from training in the use of AT.

"Disability" is an evolving concept [15] and so is ID, any attempt to precisely define the term risks to be incomplete or rapidly outdated.

Therefore, in this article "Intellectual Disability" refers to an individual's reduced ability to comprehend new or complex information [16].

The term "People with Intellectual Disability" is an umbrella term inclusive of "any form of mental health or intellectual impairment or developmental condition that is characterized by significant deficits in intellectual functioning, adaptive behavior, as well as conceptual, social and practical skills" [17, 18, 19].

In this article, sometimes the term has been replaced by the term "learners", in order to avoid any form of redundancy throughout the paragraphs. People with ID in the context of this article become "learners" at the moment they start to engage with technology.

It was decided to focus on this particular audience because they can take advantage of the technology innovations more than other vulnerable groups ${ }^{7}$ that, not necessarily living with a lifelong disability such as elderly people, can benefit from AT.

The primary purpose of AT as stated by the WHO "is to maintain or improve an individual's functioning and independence to facilitate participation and to enhance overall well-being", The aim of this article therefore is to describe a simple instrument for the designers of training to develop programs and curricula addressed to people with ID. These help people with ID to acquire the proper skills to effectively use new technological solutions, although the methodology described has wider validity.

\subsection{Inclusive Educational Environments}

"Inclusive educational environments" in this article refers to all educational settings where AT learning may take place? These include formal contexts such as schools, in-formal and non-formal context such as local services, voluntary associations and organizations aiming to enhancing the inclusion of people with ID [20].

Embracing inclusive education normally implies a clear commitment against a culture of exclusion, recognizing

\footnotetext{
7 As stated by the European Quality Assurance in Vocational Education and Training (EQAVET), vulnerable groups are "groups that experience a higher risk of poverty and social exclusion than the general population. Ethnic minorities, migrants, disabled people, the homeless, those struggling with substance abuse, isolated elderly people and children all often face difficulties that can lead to further social exclusion, such as low levels of education and unemployment or underemployment".

Available at: http://www.eqavet.eu/qc/gns/glossary/v/vulnerable-group.aspx

8 http://www.who.int/disabilities/technology/en/

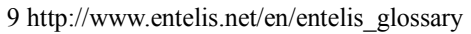

different needs, objectives and opportunities, and providing vulnerable groups with special needs with adequate support as well as technological solutions [21].

That means creating environments that do not only aim to include, but also aim to provide educational instruments to overcome the barriers, complexities and contradictions in modern society characterized by technological advancements.

A fulfilled Inclusive Education approach, ensures that the gains achieved for one person in a vulnerable situation become beneficial for all, regardless the conditions of exclusion [22].

As everyone learns differently a truly inclusive educational environment should be able to differentiate the educational proposal, tailoring and delivering opportunities on the base of specific needs of single learner. Moreover, when it customizes learning' experiences for specific learners, it needs to build upon their strengths and help them to develop and improve the understanding of notions with which they are struggling.

This includes the assessment of the learned through formative assessments and descriptive feedback.

The most effective way to build an inclusive learning environment comes from forming meaningful connections with concepts and between learners [23], by taking some extra time and effort to view each learner as an individual and by truly believing that each of them can succeed in acquiring skills [24].

\section{Methodology for Design Learning Programs in AT}

The methodology provided to design learning programs is inspired by the outcomes of the KPT project. That project developed guidelines for lifelong learning in AT. Although the guidelines address the design of learning programs for professionals, the methodology is useful for supporting the learning of learners of all ages with disabilities in schools or any other educational environments [25].

The methodology can be considered exhaustive for both creating holistic learning pathways and the design of specific personalized learning programs responding to ascertained training needs in areas of application of AT, such as employment, social life, independent living.

A practical example showing how this methodology is currently adopted, shaped and adapted, is the project "Empowerment of youth with Intellectual Disabilities through Educational and training curricula for Acquiring employment Skills" (E-IDEAS) ${ }^{10}$.

This research project funded by charity RESPECT and the Marie Curie Actions of the EU 7FP, aims to develop a transition program to empower young individuals with ID for the acquisition of employment skills and for having real work experiences. In this case, the focus of the learning program is

10 http://www.assistid.eu/fellows/presentations-files/Ivan-Traina.pdf 
on job-related skills that youths with ID could acquire by using ICT-AT. The methodology presented is applied to develop a transition program from school to the Labor Market. In the program employment skills and use of ICT-AT are merged.

\subsection{Framework of Reference}

The framework presented in Figure 1 intends to provide a flexible and simple methodology. It is based on different aspects of the learning process that designers should consider while planning and delivering training activities.

It includes considerations related to the involvement of the person, family, carers and educators, prior learning, learning dimensions, along with the definition of aims and objectives, learning outcomes, methods of delivery and assessment.

Because the needs of those involved in the training and learning pathways may be very diverse, the framework is meant to be flexible and adaptable to the situation.

The outcomes of learning should ideally match with what learners need to know, or do, with their new competencies. Learning should not only impact on the development of knowledge and skills, but also on other aspects of the learners' life.

It is important that strategies are developed to ensure this impact is reached.

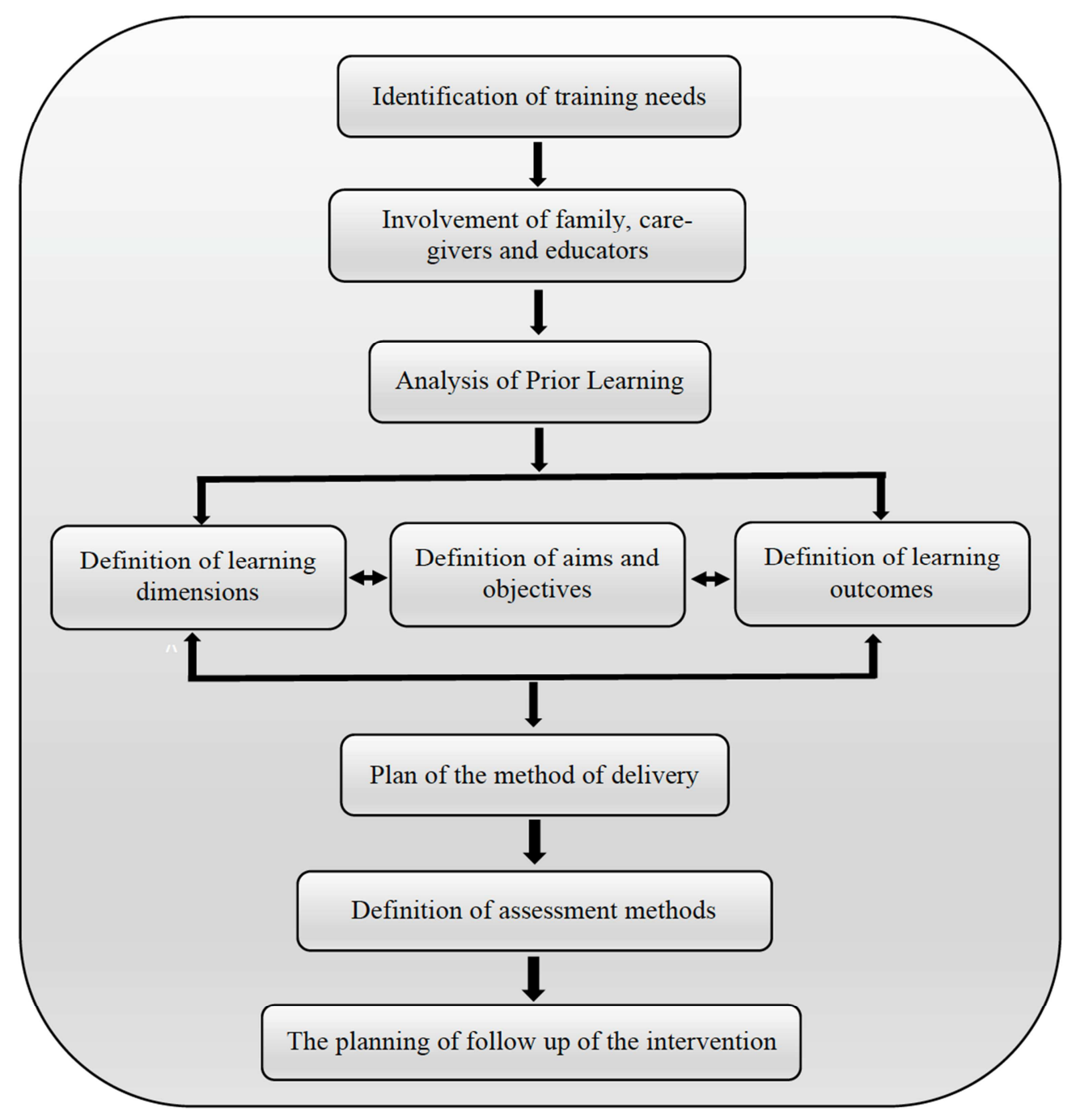

Figure 1. Framework for the design of learning programs in AT.

\subsection{Identification of Training Need}

The first step for designing a learning program in ICT-AT is a solid training needs analysis, followed by a clear definition of the target audience.

Learning programs, might focus on specific areas of AT (e.g. communication, computer access, environmental control), on the use of AT in specific settings, or on a mix of these (for example communication in educational settings or environmental control in independent living projects). It might address a small or a large number of issues, depending not only on the training needs but also on the time and the resources available in the educational environment.

An understanding of the potential and actual training needs in terms of knowledge, skills and attitudes, and how those needs might best be met, will support the provision of relevant and valued training.

A central element in the process of identification of training needs involves seeking the views of the potential 
learners. This can be carried out using participatory methods such as questionnaires, group interviews, round tables and focus groups.

A training needs analysis is likely to benefit from examining all of the following issues:

1. The objectives for learning, for example the development of skills related to practical activities such as using email, producing written work, controlling the environment or for supporting participation such as accessing opportunities in education, leisure, independent living.

2. The interests and wishes of the person.

3. The amount and type of involvement in AT use.

4. The settings in which the learners will use the AT solutions identified (e.g. home, classroom, training and education establishments, community and leisure settings).

5. The bio-psycho-social condition of the learner, including additional disabilities.

\subsection{Involvement of Family, Care-Givers and Educators}

Although it is essential to discuss learning needs and the motivation for learning with the person directly involved, the involvement of formal and informal carers and significant others is recommended. They can provide valuable information about prior learning with ICT, about competences already acquired and about what, according to them, could be the next steps in the development of independence in all life areas. Moreover, through input coming from the persons that know the potential learner, it can be easier to define learning programs. These not only respond to various existing needs but also further develop the potential and soft skills where these can be facilitated by ICT-AT (e.g. communication, capacity to make choices, selfadvocacy, etc.).

Becoming efficient in the use of AT means increasing one's level of independence and creating for oneself more opportunity in social life, education and employment [26].

Ways to involve parents and other carers include focus groups, round tables, interviews or questionnaires for collecting data. The information collected will not only help to identify the training needs, but also provide indications on the content of the training and the way of delivery.

\subsection{Analysis of Prior Learning and Existing Competences}

In order to make learning effective the recognition of prior learning is important, as well as an assessment of knowledge, skills and competencies that an individual learner already possesses [27, 28, 29]. The identification of existing competencies allows the personalization of further learning and makes it more efficient. The outcomes of learning should ideally match with what learners need to know, or do, with their previous and new competencies.

In the current digital society, where often some technological competences are acquired in formal, nonformal and informal education contexts, training proposals in
ICT-AT will rarely start from scratch.

\subsection{Definition of Aims and Objectives}

An aim is an overarching principle that guides decision making and tends to be long on direction, and short on specific tactics. Aims should focus on outcomes that are important to the individual [30]. They should be functional and based on principles of community inclusion, selfdetermination and economic self-sufficiency.

They are driven by assessments; both formal and informal, and reflect ways to help individuals overcome barriers to full community participation.

The following questions are helpful to ask when discussing potential aims:

1) Is it something the person and/or guardian wants?

2) Will it increase the number of places and people in the person's life?

3) It is age appropriate? (e.g. children, young, young adult, middle age)

4) Will it impact positively on the person's quality of life and will there be opportunities to put the learned in practice?

5) Will it enhance the person's physical condition?

6) Will it result in increased competence or status enhancement?

To help learning designer to stay on track, it is important to ask: "What is preventing the person from achieving this aim?" In other words, what are the barriers in place that are keeping the person from achieving the aim?

Assessing these barriers and developing aims and/or objectives can help to overcome these barriers.

After aims are chosen and prioritized by the individual in collaboration with their support team, learning objectives are developed to assist the individual to achieve those goals. Learning objectives help to determine if progress is being made toward that end.

The learning objectives are the stepping stones to goal achievement. Aims should be based on individual's wants/needs/desires and are very general. Learning objectives are an organized, logical pathway to reach the aim and must be written so that they are measurable.

Considering the theme of this article, it is important to specify that Learning objectives are referred to as "behavioral", "teaching," or "training" objectives. A learning objective is an attempt to clearly define the criteria for successful completion of a skill.

\subsection{Definition of Learning Dimensions}

In order to simplify the design of the learning strategy, it is useful to consider whether the progression in the learning is defined by the level of autonomy, especially in the case of person with ID. This is shown by the revised Bloom's Taxonomy ${ }^{11}$, that includes four dimensions which move on the spectrum ranging from concrete to abstract knowledge:

1) Factual dimension: this dimension covers knowledge of

11 http://www.celt.iastate.edu/teaching/effective-teaching-practices/revisedblooms-taxonomy 
terminology, specific details and elements.

This dimension is relevant for learners (and their immediate support network, as formal and informal carers, educators) who aim towards having basic knowledge of the use of personal AT solutions and very basic skills in using them, where necessary with high levels of support.

2) Conceptual dimension: this dimension involves knowledge of classifications and categories, principles and generalizations, theories, models, and structures.

This dimension is relevant for learners who aim towards having adequate knowledge of personal AT solutions and appropriate skills in using them proficiently with little or no support.

3) Procedural dimension: this dimension refers to knowledge of subject-specific skills, techniques and methods and of criteria for determining when to use appropriate procedures.

This dimension is relevant for learners who aim towards having in-depth knowledge and critical awareness of personal AT solutions and proficient skills in using these independently (this does not exclude support in setting up the AT solution) to increase their level of activity and participation.

4) Metacognitive dimension: this dimension involves strategic knowledge about cognitive tasks and selfknowledge.

This dimension is relevant for learners who aim towards having wider knowledge on ICT-AT solutions for a wide range of other users in order to be able to support them appropriately.

\subsection{Definition of Learning Outcomes}

Learning outcomes are what learners will or should be able to understand or do following completion of a training or learning program. As stated by European Commission in the European Qualification Framework (EQF) ${ }^{12}$ a learning outcome is "the set of knowledge, skills and/or competencies an individual has acquired and/or is able to demonstrate after completion of a learning process. Learning outcomes are statements of what a learner is expected to know, understand and/or be able to do at the end of a period of learning" [31].

As previously mentioned, specific learning outcomes might be addressed at different dimensions. For example, a learning outcome concerning the core principles of AT can be addressed to three learning dimensions:

1) Factual dimension: acknowledge of the core principles of the AT and having awareness of the use of personal AT solutions and very basic skills in using them.

2) Conceptual dimension: explain and discuss the features of the core principles of AT and knowledge of personal AT solutions and adequate skills in using them proficiently with little or no support.

3) Procedural dimension: evaluate the issues involved in

12 http://www.cedefop.europa.eu/it/events-and-projects/projects/europeanqualifications-framework-eqf the core principles of AT and having in-depth knowledge and awareness of personal AT solutions and proficient skills in using these independently to increase their level of activity and participation.

Not all learning outcomes should necessarily address the same dimension. Specific learning outcomes can match with different dimensions, especially if training is on an as-needed basis or uses a person-centred approach.

\subsection{Methods of Delivery}

The learning outcomes can be achieved in a variety of ways, through different methods of delivery including:

1) Face-to-face interactions: is a traditional approach and there are a range of strategies for supporting as: lectures, small group work, role-play and experiential learning and active participation (e.g. group discussion, problem-solving, examination of real-life examples, etc.).

2) Distance learning and web-based courses: with the advance of e-learning, distance learning and web-based courses are becoming a popular alternative way of learning. Using AT is often very "hands-on", especially regarding access issues, distance learning will in most cases need to be supplemented by face-to-face sessions, with the possibility of handling and using equipment. For distance learning, video will be helpful to illustrate issues.

3) Individual practice, research and reading: these are traditional methods for supporting the execution of practical tasks, co-participating in making focus on specific themes to search, reading, explaining and simplifying instructions.

4) Experiential learning and associated reflection: deep learning and the maximizing of reflective practice.

This approach is upheld by current adult learning theory [32] which strongly supports the benefits of experiential learning and associated reflection, with opportunities to examine and experiment with ongoing support.

The following suggestions may also be helpful in delivering training activities addressed to people with ID for achieving successful learning:

1) Where appropriate a range of relevant equipment should be available and set up so that it can be used by learners.

2) There should be plenty of time for "hands-on" practice (e.g. using equipment, using software, connecting up hardware).

3) Case studies, especially with the use of photographs and video clips, can help highlight issues and can also be used for interactive problem-solving sessions.

In addition to thinking of the different methods to enable learners to achieve the learning outcomes, the ways in which different people learn best needs to be considered and catered for.

In an inclusive educational environment, the setting is created and determined by the needs of the learners, the accessibility of resources and the methods used for delivering the knowledge content. It is likely that providing a variety of learning experiences will promote participants' learning.

Moreover, it is helpful to consider the active role of learner, that means what he/she does and learns is actually 
more important than what the teacher or trainer does.

The total amount of time required to achieve the learning outcomes and the relative proportion of time that learners spend in activities such as face-to-face sessions, home study, work-based learning etc. has implications for the resources used and need to be carefully planned.

\subsection{Defining Assessing Methods}

The methods of assessment should be planned at the beginning of the learning process.

The learning outcomes should be written in such a way that they demonstrate what should be assessed and what method will be used.

The assessment should be commensurate with the learning outcomes using a formative assessment approach [33]. As for people with ID to be actively involved in their learning means understand a learning goal, aim for it, and use assessment evidence to stay on course and partner with their teachers/trainers to achieve successful learning outcomes [34].

It means considering the assessment as a process that can be enforced by the feedback collected during the teaching/training activities and not to rank learners.

Following are two examples of formative assessment that can be used with people with ID:

(a) Fingers Up: a quick way to assess understanding during a lesson is to say fingers up! The number of fingers learners hold up, assuming they are able to perform this act, corresponds to how well they understand the lesson.

For example:

1. finger up: I need a lot of help understanding

2. fingers up: I need some help understanding

3. fingers up: I mostly understand, but could use a little help

4. fingers up: I understand the lesson

5. fingers up: I understand the lesson very well and could teach it to another student

(b) Exit Tickets: an exit ticket is distributed to learners at the end of a learning unit or period. The teacher/trainer poses a question about the lesson and asks students to respond on a piece of paper, a digital device or any other high or low-tech communication means matching theo the abilities of the learners with ID.

Some examples of questions are:

1. What is one thing you learned today?

2. What is one question you have about this topic?

3. What is something you'd like to learn more about?

4. What is one task your group accomplished today?

5. What are three adjectives that describe your best friend?

6. What are the first two steps of the scientific method?

\subsection{The Planning of Follow Up of the Intervention}

After delivery of the intervention it is helpful to allow time for reflection and for learners to put new knowledge and skills into practice, in order to consider how their training has affected their confidence and use of AT.
This process can be greatly enhanced by organizing follow-up sessions after the end of the learning program (e.g. after 6 months).

The way in which a follow-up is designed is likely to be influenced by the type of learning program that was initially delivered.

Moreover, some methods of collecting feedback (e.g. focus groups, interviews and questionnaires) and tools of communication (e.g. web-based forums, telephone conference calls or video-conferencing) may provide useful and cost-effective ways of supporting the follow up activities.

\section{Discussion}

There is a broad consensus worldwide about the benefits that people with ID can receive through the appropriate use of evolving information and communication technologies [35]. This debate includes also how to stimulate the advancement in the acquisition of knowledge and competence for using AT by people with ID.

Furthermore, international documents [36, 37, 38] suggest ways by which digital technology can be used in schools or any other educational environment to promote personalized learning (e.g. customized instructions, curricula, assessment) and change classroom organization. The purpose of these changes is to access digital learning content and to interact with other learners, parents and experts.

Considering that educational and AT service delivery systems and practices across Europe are disparate, the learning programs should respect local differences and individual learner needs [39] that through this tool can be guarantee.

The methodology presented is flexible and easily customizable and thus allows for a person-centred approach.

Training in the use of AT is only one stage for their adoption process that consists of needs analysis, matching the person to the technology, choice, acquisition and installation, personalization and training.

For instance, the MeAc-inquiry [40] on the use of assistive technology by visually impaired people concluded that only $27.2 \%$ count on disability specific solutions (meaning assistive technology). It is estimated that in Western countries (US and Europe) about one-third of the AT solutions recommended are abandoned or unused [41]. This means that there is still a lot of work to be done to close the gap between the opportunities offered by the technology and their actual spread and use. This methodology is precisely aimed to bridge this existing gap, trying to provide educational staff with an instrument for designing training interventions for the use of AT.

Further insufficient awareness and inappropriate competence can reduce the benefits of new technologies. If people with ID, their parents or carers are not able to understand or use available solutions, it may lead to aversion, thus creating barriers to the adoption of technology, precluding important opportunities for inclusion and 
participation [42].

In many welfare systems, the choice and provision of AT is in the hands of professionals [43]. Beneficiaries are often only slightly involved and less trained. If training is provided it is often limited to information based on a manual with the installation of the devices in the home situation.

Getting used to a new technology is a complex process that involves many factors. The experience is that most learners need more and individualized training and support to be able to turn new technological solution in real opportunities.

Therefore, teachers/trainers/educators, if use a flexible methodology to plan activities for an appropriate training, can guarantee the necessary support for the acquisition of knowledge and skills necessary to use AT [44, 45].

Providing training opportunities to people with ID complies with the actual paradigm of self-determination and the empowerment of vulnerable groups as well as reducing the digital divide $[46,47]$.

\section{Conclusion}

As ICT-AT are personalized solutions for individual needs, learning pathways should be implemented where possible on an individual basis, using a person-centred approach, taking into account the life goals and all relevant contexts for people with ID.

Aiming at independent use of AT involves that people are aware of their needs and of the possibilities offered by their solutions. Training is therefore key. People are interested in AT and would like to further expand their knowledge, going beyond limits, socio-cultural barriers and low expectations. Training in the use of AT should not be limited to knowing how it works, but people with ID should also be skilled in the use of assistive devices to reach other goals, in order to enhance their potential. Moreover, their learning about other areas of AT, not directly relevant to themselves, may become beneficial for parents, for peers, for associations, for wider administrative as well as social, cultural and economic sectors, where people with ID should participate on an equal base.

\section{Acknowledgements}

This research was supported by funding from the charity RESPECT and the People Programme (Marie Curie Actions) of the European Union's Seventh Framework Programme (FP7/2007-2013) under REA grant agreement no. PCOFUND-GA-2013-608728

\section{References}

[1] Gardiner, K., Herault, Y., Lott, I. T., Antonarakis, S. E., Reeves, R. H., \& Dierssen, M. (2010). Down syndrome: from understanding the neurobiology to therapy. Journal of Neuroscience, 30(45), 14943-14945.

[2] World Health Organization Executive Board. Resolution
EB142. R6 (2018). Improving access to assistive technology. Geneva, Switzerland: World Health Organization.

[3] Copley, J., \& Ziviani, J. (2004). Barriers to the use of assistive technology for children with multiple disabilities. Occupational Therapy International, 11(4), 229-243.

[4] Committee on Accreditation Rehabilitation Engineering and Assistive Technology Education, RESNA-CAAHEP (2016). Standards and guidelines for the accreditation of educational programs in assistive technology [Internet]. Available at: http://www.caahep.org/CAAHEP/media/CAAHEP-

Documents/AssistiveTechnologyStandards.pdf

[5] Burgstahler, S. (2009). Universal Design of Instruction (UDI): Definition, Principles, Guidelines, and Examples. DO-IT.

[6] Rose, D. H., \& Meyer, A. (2002). Teaching every student in the digital age: Universal design for learning. Association for Supervision and Curriculum Development, $1703 \mathrm{~N}$. Beauregard St., Alexandria, VA 22311-1714.

[7] UNESCO, (2011). ICT competency framework for teacher. Paris Available at: http://unesdoc.unesco.org/images/0021/002134/213475e.pdf

[8] Fullan, M. and Langworthy, M., (2014). A Rich Seam: How New Pedagogies Find Deep Learning. London: Pearson.

[9] European Agency for Development in Special Needs Education, (2013). Information and Communication Technology for Inclusion - Developments and Opportunities for European Countries. (A. Watkins, ed.). Odense, Denmark.

[10] European Agency for Special Needs and Inclusive Education, (2016). Raising the Achievement of All Learners in Inclusive Education - Literature Review. (A. Kefallinou, ed.). Odense, Denmark.

[11] OECD, (2010). Inspired by Technology, Driven by Pedagogy: A Systematic Approach to Technology-Based School Innovations. Centre for Educational Research and Innovation. Paris: OECD Publishing.

[12] High-frequency trading (HFT). Using personalised technology to enable transition - how personalised technology, including assistive technology and telecare, has enabled the transition from registered care to support living for individuals with learning disabilities. J Assist Technol 2010; 4:46-50.

[13] UNESCO, (2004). Changing teaching practices using Curriculum Differentiation to Respond to Students Diversity.

[14] Owuor, J., Larkan, F., \& MacLachlan, M. (2017). Leaving noone behind: using assistive technology to enhance community living for people with intellectual disability.

[15] UN, (2006). Convention on the Rights of persons with Disability, G. A. Res. 61/106, Dec. 13, 2006. Available at: http://www.un-documents.net/a61r106.htm

[16] Bigby, C., \& Ozanne, E. (2001). Shifts in the model of service delivery in intellectual disability in Victoria. Journal of Intellectual and Developmental disability, 26(2), 177-190.

[17] Schalock, R. L., Buntinx, W. H. E., Borthwick-Duffy, S., Bradley, V., Craig, E. M., Coulter, D. L., Yeager, M. H. (2010). Intellectual disability: Definition, classification, and system of supports (11e). Washington, D. C.: American Association on Intellectual and Developmental Disabilities. 
[18] American Psychiatric Association (2013). Diagnostic and Statistical Manual of Mental Disorders (5th ed.). Arlington, Virginia: American Psychiatric Publishing.

[19] World Health Organisation. Definition: intellectual disability. 2017. Available at: http://www.euro.who.int/en/healthtopics/noncommunicable-diseases/mentalhealth/news/news/2010/15/childrens-right-to-familylife/definition-intellectual-disability

[20] Sheehy, K. (2005). ICT and special educational needs: a tool for inclusion. British Journal of Learning Disabilities, 33(4), 206-207.

[21] Standen, P. J., Brown, D. J., \& Cromby, J. J. (2001). The effective use of virtual environments in the education and rehabilitation of students with intellectual disabilities. British Journal of Educational Technology, 32(3), 289-299.

[22] UNESCO, (2000). Section for Special Needs Education, Inclusive Education and Education for All. A challenge and a vision. Paris.

[23] Salend, S. J. (2015). Creating inclusive classrooms: Effective, differentiated and reflective practices. Pearson.

[24] Ahmad, F. K. (2015). Use of assistive technology in inclusive education: Making room for diverse learning needs. Transcience, 6(2), 62-77.

[25] Perelmutter, B., McGregor, K. K., \& Gordon, K. R. (2017). Assistive technology interventions for adolescents and adults with learning disabilities: An evidence-based systematic review and meta-analysis. Computers \& education, 114, 139163.

[26] Groff, J. (2013). Technology-rich innovative learning environments. OCED CERI Innovative Learning Environment project, 1-30.

[27] Harris, J. (1999). Ways of seeing the recognition of prior learning (RPL): What contribution can such practices make to social inclusion? Studies in the Education of Adults, 31(2), 124-139.

[28] Bowman, K., Clayton, B., Bateman, A., Knight, B., Thomson, P., Hargreaves, J., \& Enders, M. (2003). Recognition of prior learning in the vocational education and training sector. National Centre for Vocational Education Research.

[29] Andersson, P., Fejes, A., \& Sandberg, F. (2013). Introducing research on recognition of prior learning. International Journal of Lifelong Education, 32(4), 405-411.

[30] Bateman, B. D., \& Herr, C. M. (2011). Writing measurable IEP goals and objectives. Attainment Company Inc.

[31] European Commission, (2005). Towards a European Qualifications Framework for Lifelong Learning [Commission Staff Working Document] (SEC (2005) 57, July 2005), 4-11.

[32] Fry, H., Ketteridge, S. and Marshall, S., (2003). Understanding Student Learning. In: Fry, H., Ketteridge, S. and Marshall, S. (eds.) A Handbook for Teaching and Learning in Higher Education 2nd Ed. (Routledge Falmer, London, 2003)

[33] Shepard, L. A. (2000). The role of assessment in a learning culture. Educational researcher, 29 (7), 4-14.

[34] Brookhart, S. \& Lazarus, S. (2017). Formative Assessment for
Students with Disabilities. Commissioned by the Council of Chief State School Officers State Collaboratives on Assessing Special Education Students and Formative Assessment, Washington, DC.

[35] Owuor, J., Larkan, F., Kayabu, B., Fitzgerald, G., Sheaf, G., Dinsmore, J., \& MacLachlan, M. (2018). Does assistive technology contribute to social inclusion for people with intellectual disability? A systematic review protocol. BMJ open, 8 (2), e017533.

[36] Digital Agenda for Europe, (2010). Communication from the Commission to the European parliament, the Council, the European Economic and Social committee and the Committee of the Regions. (COM (2010) 245 final).

[37] UNESCO IITE, (2012). Personalized Learning: A New ICTEnabled Education Approach. IITE Policy Brief, March 2012. Moscow: UNESCO IITE. Available at: http://iite.unesco.org/pics/publications/en/files/3214716.pdf

[38] European Commission, (2013). Opening up Education: Innovative teaching and learning for all through new Technologies and Open Educational Resources/*COM/2013/0654 final*/. Available at: http://eurlex.europa.eu/legal-intent /EN/TXT/?uri=CELEX\%3A52013DC0654

[39] Roe, P. R. W., (2001). Bridging the Gap? Swiss Federal Institute of Technology of Lausanne.

[40] European Union, (2008). MeAC - Measuring Progress of eAccessibility in Europe: Assessment of the Status of eAccessibility in Europe. Main Report Empirica. Available at: $\mathrm{http} / / /$ ec.europa.eu/information_society/newsroom/cf/dae/doc ument.cfm?doc_id $=1188$

[41] Federici, S., Scherer, M. J. (2017). Assistive technology assessment handbook. CRC Press: Boca Raton, FL.

[42] Raja, D. S. (2016). Bridging the disability divide through digital technologies. Background paper for the World Development Report.

[43] MacLachlan, M., Banes, D., Bell, D., Borg, J., Donnelly, B., Fembek, M. \& Hoogerwerf, E. J. (2018). Assistive technology policy: a position paper from the first global research, innovation, and education on assistive technology (GREAT) summit. Disability and Rehabilitation: Assistive Technology, $1-13$.

[44] DeMonte, J. (2013). High-Quality Professional Development for Teachers: Supporting Teacher Training to Improve Student Learning. Center for American Progress.

[45] Smith, E. M., Gowran, R. J., Mannan, H., Donnelly, B., Alvarez, L., Bell, D. \& Jan, Y. K. (2018). Enabling appropriate personnel skill-mix for progressive realization of equitable access to assistive technology. Disability and Rehabilitation: Assistive Technology, 1-9.

[46] European Network for Technology Enhanced Learning in an Inclusive Society "ENTELIS", (2015). Towards full digital inclusion: the Entelis Manifesto against the digital divide. Available at: http://www.entelis.net/sites/all/files/entelis_manifesto_en.pdf

[47] Dudgeon, P., Scrine, C., Cox, A., \& Walker, R. (2017). Facilitating empowerment and self-determination through participatory action research: Findings from the National Empowerment Project. International Journal of Qualitative Methods, 16(1), 1609406917699515. 